\title{
Mammals of Prince Edward Island and Adjacent Marine Waters
}

By Rosemary Curley, Donald F. McAlpine, Dan McAskill, Kim Riehl, and Pierre-Yves Daoust. 2019. Island Studies Press. 354 pages, 49.95 CAD, Paper.

Ok, go ahead, judge this book by its cover ... it is quite stunning! A Red Fox (Vulpes vulpes), seemingly just aroused from its slumber to look at the photographer ... its tail wrapped around itself, while resting on the snow ... what a perfect shot to entice a shopper to take a copy off the bookstore shelf!

This is a thorough book-over 1000 references were used! The introduction provides a background and synopsis of Prince Edward Island's mammals, covering both extirpations and (re)introductions. Large-scale factors influencing mammals, including climate change and white-nose syndrome, are introduced; these are treated in more depth further in the book. Here, domestic animals are given mention, and dismissed from further representation in the book.

This book covers 57 species of mammal, essentially split evenly between the marine and terrestrial environments. I believe one is missing, but I'll defer that discussion. Each account includes a colour illustration of the animal, a range map (North American distribution, or beyond), and a diagram of the skull from three perspectives (dorsal, palatal, and lateral). Sometimes, there is also a photograph. For most nonvolant, terrestrial species, at least one trackway, and an accompanying more-detailed illustration of a hind and fore footprint, are included. Five of these trackways appear only as series of irregular grey shapes, clearly a printing error, for which there was no excuse; one hopes that a second printing clears this up.

The text for each account is very well organized and the writing is clear and consistent, not a small feat for a book with so many authors. Short sections include description, range, and status (now and earlier) whereas most of the accounts encompass the species' ecology, often running several pages. History on the island is detailed, which, when appropriate, includes introduction and extirpation dates and details of these events.

The missing species from this book is the Domestic (free roaming) Cat (Felis catus). Other introduced species are included-Bobcat (Felis rufus), Brown Rat (Rattus norvegicus), Eastern Gray Squirrel (Sciurus carolinensis) — so why not the infinitely problematic free roaming house cat? In Prince Edward Island, just like other jurisdictions, there are not only individuals who let their cats run amok, there are still those misguided people who promote supported colonies of these wildlife destroyers. Omitting the Domestic Cat from this book was a missed opportunity for further education.

This book is well-suited to people with a general interest (an extensive glossary was included, and will be much appreciated), but adept naturalists will still learn a lot. The previously mentioned voluminous reference section will serve as a start to finding more information for mammal enthusiasts of any level.

RANDY LAUFF

Biology, St. Francis Xavier University Antigonish, NS, Canada

(C) The author. This work is freely available under the Creative Commons Attribution 4.0 International license (CC BY 4.0). 